\title{
Effect of drying methods and parameters on the antioxidant properties of tea (Camellia sinensis) leaves
}

\author{
A. S. Roslan ${ }^{1}$, A. Ismail ${ }^{1 *}$, Y. Ando ${ }^{2}$ and A. Azlan ${ }^{1}$
}

\begin{abstract}
Background: Conventional drying using heated air oven is commonly used as a method for preserving the product but often affects the nutritional value, taste, and texture. However, the heat from the drying method can oxidize and destroy heat-sensitive compounds. Superheated steam (SHS) drying uses superheated steam instead of hot air or combustion gases in a direct dryer and was reported better at preserving the nutritional values of food products.

Aim: To evaluate the effect of SHS drying on antioxidant properties of tea leaves. The study also compared SHS drying with conventional and freeze-drying methods.

Results: Tea leaves dried using freeze drying retained the highest level of antioxidant properties compared to other drying methods. The leaves dried using SHS exhibited significantly higher radical scavenging activity, ORAC and FRAP values compared to oven drying method. At different drying temperatures $\left(150^{\circ} \mathrm{C}\right.$ and $\left.175^{\circ} \mathrm{C}\right)$, oven dried leaves showed significantly higher $(p<0.05)$ antioxidant properties than that of SHS dried ones. Tea leaves dried for 60, 75, and 90 min using SHS showed significantly higher $(p<0.05)$ FRAP and ORAC values, and also total phenolic content compared to oven dried tea leaves.

Conclusion: Tea leaves dried using SHS drying method retained higher level of antioxidant properties compared to oven drying. The drying method also retained lower antioxidant properties as drying time increased. Further study involving SHS drying in food-related fields should be conducted to support its usefulness.
\end{abstract}

Keywords: Camellia sinensis, Superheated steam drying, Antioxidant capacity, Drying method

\section{Introduction}

The tea plant (Camellia sinensis) is a member of the Theaceae family, and is used to make the beverage known as tea. The plant is native to Southwestern China from where it spread to central China and southern Japan 1000-2000 years ago (Prabhakaran Nair 2010). Nowadays, tea is widely grown throughout Asia, Africa and various parts of Middle East (Chopade et al. 2008; Mahmood et al. 2010). The different types of tea available in the market are manufactured from the leaves of the Camellia sinensis. Differences in the processing

\footnotetext{
* Correspondence: aminis@upm.edu.my

${ }^{1}$ Department of Nutrition and Dietetics, Faculty of Medicine and Health

Sciences, Universiti Putra Malaysia, 43400 Serdang, Selangor, Malaysia

Full list of author information is available at the end of the article
}

method and fermentation level can produce different types of tea for consumption ( $\mathrm{Li}$ and $\mathrm{Zhu} 2016$; Yuan et al. 2011). Three main types of tea produced are nonfermented tea, semi-fermented tea, and fermented tea. Other types of tea include white, yellow, and Pu-erh tea.

Conventional drying using an air oven is a common method for drying food products but often affects the nutritional value, taste, and texture. In addition, this drying method can oxidize and destroy heat-sensitive polyphenols (Kaur and Singh 2014; Nistor et al. 2017), causing the product to lose most of its antioxidant properties (Hwang and Thi 2014; Li et al. 2017). The superheated steam (SHS) drying was reported to be potentially better at preserving the nutritional value of the food (Somjai et al. 2009; Rumruaytum et al. 2014). SHS drying uses superheated

(c) The Author(s). 2020 Open Access This article is licensed under a Creative Commons Attribution 4.0 International License, which permits use, sharing, adaptation, distribution and reproduction in any medium or format, as long as you give appropriate credit to the original author(s) and the source, provide a link to the Creative Commons licence, and indicate if changes were made. The images or other third party material in this article are included in the article's Creative Commons licence, unless indicated otherwise in a credit line to the material. If material is not included in the article's Creative Commons licence and your intended use is not permitted by statutory regulation or exceeds the permitted use, you will need to obtain permission directly from the copyright holder. To view a copy of this licence, visit http://creativecommons.org/licenses/by/4.0/. 
steam instead of hot air or combustion gases in a direct dryer. It had been applied on a variety of food more regularly nowadays as no oxidative reactions can occur, hence preserving the colour and nutrients of food. Study on the treatment of agricultural products had reported better quality when using the superheated steam instead of hot air drying (Zzaman et al. 2013).

In this study, SHS drying was compared to conventional oven and freeze drying methods, focusing on the amount of antioxidants in the leaves after subjected to each drying methods. In addition, the leaves were dried at different drying temperatures and times in order to evaluate the effects of those parameters on the antioxidant content of the studied sample.

\section{Materials and methods}

\section{Chemicals and reagents}

Iron (III) chloride hexahydrate $\left(\mathrm{FeCl}_{6} \cdot 6 \mathrm{H}_{2} \mathrm{O}\right)$, sodium carbonate $\left(\mathrm{Na}_{2} \mathrm{CO}_{3}\right)$, sodium hydroxide $(\mathrm{NaOH})$, sodium nitrate $\left(\mathrm{NaNO}_{3}\right)$ iron (II) sulphate $\left(\mathrm{FeSO}_{4}\right)$, and aluminium chloride $\left(\mathrm{AlCl}_{3}\right)$ were purchased from Sigma-Aldrich Corporation (USA). Pyrogallol red, 2,2diphenylpicrylhydrazil (DPPH), azo-bis(2-amidinopropane) dihydrochloride (AAPH), 6-hydroxy-2,5,7,8-tetramethylchroman-2-carboxylic acid (TROLOX), Folin ciocalteu reagent, gallic acid and quercetin were purchased from Sigma-Aldrich Corporation (USA). 2,4,6-Tris(2-pyridyl)-s-triazine (TPTZ) was purchased from Fluka Analytical (Germany). Hydrochloric acid $(\mathrm{HCl})$ was puchased from R\&M Chemicals (Malaysia). Absolute Ethanol was purchased from Systerm Chemicals (Malaysia). Acetic acid was purchased from Thermo Fischer Scientific (USA).

\section{Sample preparation}

Camellia sinensis leaves were collected from $\mathrm{BOH}$ Tea Plantation in Cameron Highlands, Malaysia. Two kilograms of leaves were collected and healthy and undamaged leaves were selected and transported to the Nutrition laboratory at Universiti Putra Malaysia (UPM). The leaves were immediately subjected to the drying methods (freeze, oven, superheated steam). In addition, the leaves undergoing conventional oven and superheated steam drying were also dried at different temperatures and time. The dried samples were ground using a commercial blender from Waring Commercial (Connecticut, USA) and sieved through a $0.025 \mathrm{~mm}$ sieve to get a uniform particle size. The powdered samples were used for antioxidant capacity, total phenolic and flavonoid content determinations.

\section{Methods of drying}

Drying was done using both conventional and superheated steam (SHS) oven (DC Quto QF-5200C Steam oven from Naomoto Corporation, Japan) set at different temperatures and conducted 3 times, independently.
The drying process was carried out according to Rafidah et al. (2014) with slight modifications.

The sample (100 g) was weighed and placed on the drying tray. Temperature of the conventional oven was set at $125^{\circ} \mathrm{C}$, while a temperature of $100^{\circ} \mathrm{C}$ was set for the SHS oven, and it's steam temperature at $125^{\circ} \mathrm{C}$. At different drying temperatures, the sample was dried for $1 \mathrm{~h}$. The drying was repeated at 150 and $175^{\circ} \mathrm{C}$. At different drying times, the sample was dried for $1,1.15$, and $1.5 \mathrm{~h}$ with the temperature set constant at $125^{\circ} \mathrm{C}$. The dried sample was used for extraction process for further analysis.

\section{Determination of antioxidant capacity}

The antioxidant capacity assays were used with the purpose of making a comparative evaluation on the effects of drying on antioxidants.

\section{Sample extraction}

The extraction was based on the method of Prasad et al. (2010) with few modifications. Dried, powdered sample $(5 \mathrm{~g})$ was weighed and transferred into a conical flask. Then, $70 \%$ ethanol $(50 \mathrm{~mL})$ was added and the mixture was placed on a temperature controlled orbital shaker at $400 \mathrm{rpm}, 30^{\circ} \mathrm{C}$ for $5 \mathrm{~h}$. After that, the mixture was centrifuged using a ROTOFIX 32A benchtop centrifuge from Hettich Global (Germany) at $6000 \mathrm{rpm}$ for $15 \mathrm{~min}$ before filtered. The supernatant was collected and kept at $-20^{\circ} \mathrm{C}$ before conducting the antioxidant capacity assays.

\section{Ferric Reducing Antioxidant Power (FRAP) assay}

FRAP assay was based on the method published by Prasad et al. (2010) and Benzie and Strain (1996). Acetate buffer was prepared by weighing $3.1 \mathrm{~g}$ of sodium acetate trihydrate, followed by the addition of $16 \mathrm{~mL}$ of acetic acid. The volume was made up to $1 \mathrm{~L}$ by adding distilled water and then the $\mathrm{pH}$ was adjusted to 3.6. 2,4,6-Tris(2-pyridyl)$\mathrm{s}$-triazine (TPTZ) solution $(10 \mathrm{mM})$ was prepared by dissolving $0.031 \mathrm{~g}$ of TPTZ in $10.0 \mathrm{ml}$ of $40 \mathrm{mM}$ hydrochloric acid, $\mathrm{HCl}$. Ferric chloride solution $(20 \mathrm{mM})$ was prepared by dissolving $0.054 \mathrm{~g} \mathrm{FeCl}_{6} \cdot 6 \mathrm{H}_{2} \mathrm{O}$ in $10.0 \mathrm{~mL}$ distilled water. Working FRAP reagent was prepared by mixing acetate buffer, TPTZ solution, and ferric chloride solution in a ratio of 10:1:1 $(\mathrm{v} / \mathrm{v} / \mathrm{v})$. The working FRAP reagent should be prepared fresh. $100 \mu \mathrm{L}$ of the sample extract was mixed with $3.0 \mathrm{~mL}$ of working FRAP reagent. The solution was mixed thoroughly and incubated at $37^{\circ} \mathrm{C}$ for $30 \mathrm{~min}$. The absorbance was measured at $593 \mathrm{~nm}$ using a UV-1800 UV spectrophotometer from Shimadzu Corporation (Japan). Duplicate standard of ferous sulphate solution at varying concentrations $(0.1 \mathrm{mM}, 0.2 \mathrm{mM}, 0.4 \mathrm{mM}$, $0.6 \mathrm{mM}, 0.8 \mathrm{mM}, 1.0 \mathrm{mM}$ ) were prepared to make a standard calibration curve. The FRAP values of the sample were expressed as $\mathrm{mM}$ of Fe (II) equivalent per gram of dry weight $\left(\mathrm{mM} \mathrm{Fe}^{2+} / \mathrm{DW}\right)$. 


\section{2,2-Diphenyl-1-picrylhydrazyl (DPPH) radical scavenging assay}

DPPH radical scavenging assay was performed based on the methods of Brand-Williams et al. (1995) with several adjustments. Firstly, $1 \mathrm{~mL}$ of $0.1 \mathrm{mM}$ DPPH solution in methanol was mixed with $1 \mathrm{~mL}$ of the sample extract $(100 \mu \mathrm{g} / \mathrm{mL})$. The mixture was incubated in the dark for $30 \mathrm{~min}$ before measuring the absorbance at $517 \mathrm{~nm}$. A mixture of $1 \mathrm{~mL}$ of the solvent used for extraction and 1 $\mathrm{mL}$ of DPPH solution were used as a control.

The inhibition percentage, $\%$, was calculated using the following formula:

Inhibition, $\%=\frac{\text { (Absorbance of Control-Absorbance of Sample) }}{\text { Absorbance of Control }} \times 100$

\section{Oxygen Radical Absorbance Capacity (ORAC) assay}

ORAC assay was done according to the methods of López-Alarcón et al. (2011). Pyrogallol Red (PGR) was used as the indicator dye and 2, 2' -Azo-bis(2-amidinopropane) dihydrochloride (AAPH) was used as peroxyl radical source. Solutions of PGR $(5 \mu \mathrm{M})$ and AAPH $(10 \mathrm{mM})$ were prepared fresh in phosphate buffer (75 mM, pH 7.4).

A reaction mixture containing $100 \mu \mathrm{L}$ of PGR and $100 \mu \mathrm{L}$ of sample (pre-diluted with Phosphate buffer if required) were prepared in a 96-well microplate. The sample was excluded from the mixture for the control and Trolox $(20 \mu \mathrm{L})$ was used as the standard. The mixture was incubated at $37^{\circ} \mathrm{C}$ for $15 \mathrm{~min}$ before $50 \mu \mathrm{L}$ of AAPH was added. PGR consumption was evaluated based on the gradual decrease in absorbance value measured at $540 \mathrm{~nm}$ using FLUOstar Omega microplate reader (BMG Labtech, Germany). The absorbance value was taken every $5 \mathrm{~min}$ until the value was reduced by $80 \%$ of its initial value. The values were plotted on an absorbance against time graph in order to obtain the area under the curve (AUC).

The ORAC value was measured based on the equation below:

$$
\mathrm{ORAC} \text { value }=\frac{\left(\mathrm{AUC}-\mathrm{AUC}^{0}\right)}{\left(\mathrm{AUC}_{\mathrm{Trolox}}-\mathrm{AUC}^{0}\right)} \mathrm{f}[\text { Trolox }]
$$

AUC $=$ area under the curve for sample $\mathrm{AUC}^{0}=$ area under the curve for control

$\mathrm{AUC}_{\text {Trolox }}=$ area under the curve for Trolox standard $\mathrm{f}=$ dilution factor

[Trolox $]=$ Trolox millimolar concentration

\section{Determination of Total Phenolic Content (TPC)}

TPC of the samples were determined using Folin - Ciocalteu method. The method was based on Prasad et al. (2010) with few modifications. The sample extract $(0.1 \mathrm{~mL})$ was transferred into borosilicate tubes, followed by the addition of $1.8 \mathrm{~mL}$ of distilled water and $0.2 \mathrm{~mL}$ of Folin - Ciocalteu reagent, and mixed well. Next, $0.5 \mathrm{~mL}$ of saturated $20 \%$ sodium carbonate, $\mathrm{Na}_{2} \mathrm{CO}_{3}$, was added and mixed, followed by the addition of $0.8 \mathrm{~mL}$ of distilled water. The mixture was allowed to react for $1 \mathrm{~h}$, and transferred into glass cuvettes. The absorbance of the sample was measured at 725 $\mathrm{nm}$. The duplicate standards of varying concentrations of gallic acid $(0.005 \mathrm{M}, 0.01 \mathrm{M}, 0.015 \mathrm{M}, 0.020 \mathrm{M}$, \& $0.025 \mathrm{M})$ were prepared as a standard calibration curve.

\section{Determination of Total Flavonoid Content (TFC)}

TFC of the samples were determined based on Baba and Malik (2015) with several modifications. Firstly, $1 \mathrm{~mL}$ of diluted sample extract was mixed with $0.4 \mathrm{~mL}$ distilled water and $0.3 \mathrm{~mL}$ of $5 \%$ sodium nitrate, $\mathrm{NaNO}_{3}$, solution and incubated for $5 \mathrm{~min}$. After that, $0.3 \mathrm{~mL}$ of $10 \% \mathrm{AlCl}_{3}$ solution was added and incubated for another $6 \mathrm{~min}$. Next, $2 \mathrm{~mL}$ of $1 \mathrm{M} \mathrm{NaOH}$ solution was added and the mixture was incubated for $15 \mathrm{~min}$ before reading the absorbance of the mixture at $510 \mathrm{~nm}$ using a UV-1800 UV spectrophotometer from Shimadzu Corporation (Japan). Different concentrations of quercetin $(1 \mathrm{mg} / \mathrm{mL}, 5 \mathrm{mg} /$ $\mathrm{mL}, 20 \mathrm{mg} / \mathrm{mL}, 40 \mathrm{mg} / \mathrm{mL}, \& 80 \mathrm{mg} / \mathrm{mL}$ ) were used to prepare a standard calibration curve. The total flavonoid value was expressed as mg of quercetin equivalent per $g$ of dried sample (mg QE per g).

\section{Identification of phenolic compound using High Performance Liquid Chromatography (HPLC)}

The method of extraction for phenolic compounds was based on the methods by Nurul Nadirah et al. (2014) with slight modifications. Dried samples $(1 \mathrm{~g})$ were subjected to direct solvent extraction using $20 \mathrm{ml}$ of $70 \%$ ethanol and $5 \mathrm{ml}$ of $1.2 \mathrm{M}$ hydrochloric acid, $\mathrm{HCl}$, was also added for acid hydrolysis. The mixture was placed on an orbital shaker at $250 \mathrm{rpm}$ for $2 \mathrm{~h}$. The sample extract was filtered and centrifuged at $4000 \mathrm{rpm}$ for 30 min. The supernatant was collected, filtered and stored at $-20{ }^{\circ} \mathrm{C}$ freezer for further use.

High Performance Liquid Chromatography (HPLC) analysis was performed based on the method by Chew et al. (2011). Separation was performed on a YMC pack pro C18 RS column at room temperature. The injection volume of the sample was $20 \mu \mathrm{l}$ and the flow rate was set at $0.6 \mathrm{ml} / \mathrm{min}$. The mobile phases used were $0.5 \%$ acetic acid (A), and 100\% methanol (B). Before the injection process, $1 \mathrm{ml}$ of the sample was filtered throuh a $0.45 \mu \mathrm{m}$ membrane filter. The applied gradient elution profile was: 0-20 min, linear gradient from 0 to $90 \% \mathrm{~B}$; 20-25 min, 90\% B isocratic; $25-30 \mathrm{~min}$, linear gradient from 90 to $0 \% \mathrm{~B}$. The wavelengths used for compound detection were 280, 254 and $329 \mathrm{~nm}$. Standards of phenolic acids (gallic acid, protocatechuic acid, chlorogenic acid, 4-hydroxybenzoic acid, ellagic acid, vanillic acid, 
trans cinnamic acid, p-coumaric acid), flavonoids (epicatechin, epigallocatechin gallate, rutin, myricetin, quercetin, naringenin), and alkaloids (caffeine, theobromine) were used as reference standard to determine several compounds in the sample.

\section{Statistical analysis}

The software used for the analysis was the SPSS version 21 and the results of the experiments were expressed as mean and standard deviations. ANOVA and Tukey's post-hoc multiple comparison test, with a significant level of $p<0.05$, were used for the antioxidant capacity, total flavonoid and total phenolic content of the sample. Independent sample t-test, with significance level set at $p<0.05$, was used to compare the results from the effect of time and temperature on TFC, TPC, and antioxidant capacity between the two methods.

\section{Results and discussion Antioxidant capacity}

Results for total phenolic, total flavonoid, and antioxidant capacity values for tea leaves are shown in Table 1 . Freeze dried leaves showed the highest TFC (80.79 \pm $0.69 \mathrm{mg}$ QE/g DW) and FRAP value $(5.07 \pm 0.01 \mathrm{mM}$ $\mathrm{Fe}^{2+} / \mathrm{g} \mathrm{DW}$ ), while SHS dried leaves had the lowest TFC $(35.43 \pm 0.23 \mathrm{mg} \mathrm{QE} / \mathrm{g} \mathrm{DW})$ and oven dried leaves had the lowest FRAP value $\left(2.07 \pm 0.01 \mathrm{mM} \mathrm{Fe}{ }^{2+} / \mathrm{g} \mathrm{DW}\right)$. The TFC value obtained in this study was higher than the value obtained from tea leaves, as reported by Nor Qhairul Izreen and Mohd Fadzelly (2013), which ranged from 19.07 to $35.17 \mathrm{mg}$ of quercetin equivalent (QE) per gram. The FRAP) values obtained was also higher than the value obtained from green tea, as reported by Hajimahmoodi et al. (2008) which ranged from 0.55 to 3.08 $\mathrm{mM}$ of ferrous ion $\left(\mathrm{Fe}^{2+}\right)$ per gram.

Freeze dried leaves also showed the highest TPC value (117.68 $\pm 0.31 \mathrm{mg}$ GAE/g DW) while SHS drying showed the lowest TPC value $(76.82 \pm 0.32 \mathrm{mg}$ GAE/g DW). A significant difference $(p<0.05)$ was observed between freeze drying and oven drying, and also between freeze drying and SHS drying. The TPC value obtained in this study was in the range of TPC values reported by Atoui et al. (2005) and Chan et al. (2010).

The highest percentage of radical scavenging activity was shown by freeze dried leaves $(93.95 \pm 0.03 \%)$ compared to oven drying $(92.28 \pm 0.03 \%)$. Radical scavenging activity of the tea leaves in this study was higher than the value reported by Abeywickrama (2015), which ranged from 69.40 to $88.50 \%$. Furthermore, SHS dried leaves had the highest ORAC value $(39.58 \pm 0.42 \mathrm{mM}$ $\mathrm{TE} / \mathrm{g} \mathrm{DW})$ than that of oven dried leaves $(18.17 \pm 0.87$ $\mathrm{mM} \mathrm{TE} / \mathrm{g} \mathrm{DW}$ ). The ORAC value obtained from this study was higher than the value reported previously by Seeram et al. (2006) and Cádiz-Gurrea et al. (2014). Significant difference $(p<0.05)$ was observed between oven drying and freeze drying, and also between oven drying and SHS drying in both assays.

Differences between the TPC, TFC, radical scavenging activity, and antioxidant capacity values obtained in this study and previous studies could be attributed to several reasons. Extraction solvent used can also affect the antioxidant capacity values of the sample. Polar solvents such as aqueous methanol or ethanol are able to extract higher amount of phenolic compounds than less polar solvents (Sultana et al. 2009; Do et al. 2014). Hence, higher antioxidant capacity values would be obtained from samples extracted using polar solvents.

\section{Phenolic compounds identification using High Performance Liquid Chromatography (HPLC)}

High performance liquid chromatography (HPLC) was used to detect selected phenolic (gallic acid, vanillic acid, ellagic acid, epicatechin, epigallocatechin gallate (EGCG), rutin, myricetin) and alkaloids (theobromine, caffeine) in the samples. The samples were spiked with the standard compounds and the UV spectra of the peaks in the sample were compared with the standard compound's UV spectra for conformation. The chromatogram of each sample is shown in Fig. 1, and the list of possible compounds present in the sample and their concentrations, expressed as milligram per gram of dry weight, is shown in Table 2.

Table 1 TPC, TFC, and antioxidant capacity of tea [Camellia sinensis (L.) Kuntze] leaves

\begin{tabular}{llll}
\hline Antioxidant Capacity Values & Drying Methods & & SHS \\
\cline { 2 - 4 } & Freeze & Oven & $76.82 \pm 0.32^{c, d}$ \\
\hline TPC (mg GAE/g DW) & $117.68 \pm 0.31^{a}$ & $77.19 \pm 0.40^{\mathrm{b}, \mathrm{d}}$ & $35.43 \pm 0.23^{\mathrm{c}}$ \\
TFC (mg QE/g DW) & $80.79 \pm 0.70^{\mathrm{a}}$ & $37.97 \pm 0.65^{\mathrm{b}}$ & $93.90 \pm 0.03^{\mathrm{a}, \mathrm{d}}$ \\
Radical Scavenging Activity (\%) & $93.95 \pm 0.03^{\mathrm{a}}$ & $92.28 \pm 0.03^{\mathrm{b}, \mathrm{c}}$ & $2.75 \pm 0.01^{\mathrm{c}}$ \\
FRAP Value (mM Fe2+/g DW) & $5.07 \pm 0.01^{\mathrm{a}}$ & $2.07 \pm 0.01^{\mathrm{b}}$ & $38.78 \pm 0.31^{\mathrm{a}, \mathrm{d}}$ \\
ORAC Value (mM TE/g DW) & $39.58 \pm 0.42^{\mathrm{a}}$ & $18.17 \pm 0.87^{\mathrm{b}, \mathrm{c}}$ & \\
\hline
\end{tabular}

Values are expressed as mean and standard deviation $(n=3)$. Different superscript in each row indicates significant difference $(p<0.05)$ based on ANOVA and Tukey's post-hoc test. (SHS = Superheated steam) 

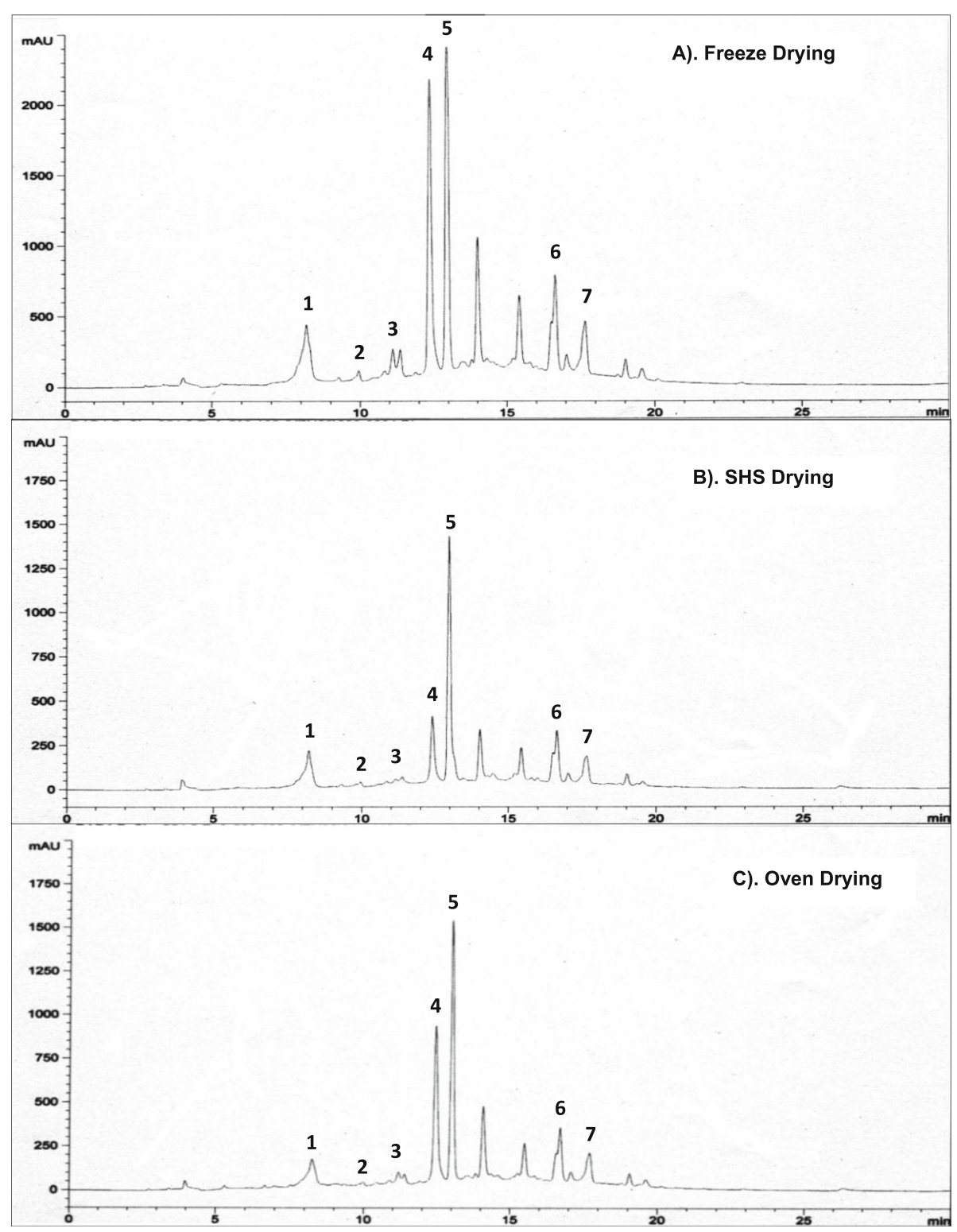

Fig. 1 HPLC Chromatogram of Tea Leaves Dried Using (a) Freeze Drying, (b) SHS Drying, and (c) Oven Drying Methods. Peaks: (1 = gallic acid), ( 2 = theobromine), $(3=$ epicatechin), $(4=$ epigallocatechin gallate (EGCG)), $(5=$ caffeine), $(6=$ rutin), $(7=$ myricetin). (SHS = Superheated steam)

Table 2 List and concentration of selected compounds detected in tea [Camellia sinensis (L.) Kuntze] using HPLC

\begin{tabular}{|c|c|c|c|c|c|}
\hline \multirow[t]{2}{*}{ Peak No. } & \multirow{2}{*}{$\begin{array}{l}\text { Retention } \\
\text { Time (min) }\end{array}$} & \multirow{2}{*}{$\begin{array}{l}\text { Compound } \\
\text { Name }\end{array}$} & \multicolumn{3}{|c|}{ Concentration (mg per g DW) } \\
\hline & & & Freeze Drying & SHS Drying & Oven Drying \\
\hline 1 & 8.219 & Gallic Acid & $5.40 \pm 0.02^{a}$ & $2.30 \pm 0.03^{b}$ & $1.77 \pm 0.06^{c}$ \\
\hline 2 & 9.967 & Theobromine & $2.61 \pm 0.02^{\mathrm{a}}$ & $1.11 \pm 0.06^{b}$ & $1.53 \pm 0.04^{c}$ \\
\hline 3 & 11.149 & Epicatechin & $3.49 \pm 0.02^{\mathrm{a}}$ & $1.02 \pm 0.03^{b}$ & $1.51 \pm 0.04^{c}$ \\
\hline 4 & 12.403 & $\begin{array}{l}\text { Epigallocatechin } \\
\text { Gallate (EGCG) }\end{array}$ & $3.98 \pm 0.04^{\mathrm{a}}$ & $1.43 \pm 0.04^{b}$ & $2.02 \pm 0.04^{c}$ \\
\hline 5 & 12.974 & Caffein & $2.79 \pm 0.02^{a}$ & $1.64 \pm 0.01^{b}$ & $1.51 \pm 0.05^{c}$ \\
\hline 6 & 16.659 & Rutin & $2.68 \pm 0.03^{\mathrm{a}}$ & $1.41 \pm 0.03^{b}$ & $1.50 \pm 0.03^{c}$ \\
\hline 7 & 17.672 & Myricetin & $2.34 \pm 0.06^{\mathrm{a}}$ & $1.04 \pm 0.03^{b, d}$ & $1.12 \pm 0.03^{c, c}$ \\
\hline
\end{tabular}

Values are expressed as mean and standard deviation $(n=3)$. Different superscript in each row indicates significant difference $(p<0.05)$ based on ANOVA and Tukey's post-hoc test. (SHS = Superheated steam 
Based on the high-performance liquid chromatography (HPLC) results in Fig. 1, Peak 1 was identified as Gallic acid, which is a common phenolic compound of tea that had been reported previously by Del Rio et al. (2004) and Kim et al. (2011). Peak 2 was identified as theobromine and its presence in tea was reported by several previous studies by Gupta et al. (2002), Del Rio et al. (2004), and Kim et al. (2011). The presence of epicatechin was also identified in the sample as Peak 3 and had been reported previously by Kim et al. (2011) and Yi et al. (2015). Peak 4 is was identified as Epigallocatechin gallate (EGCG), one of the most prevalent tea catechin found in green tea (Gupta et al.
2002; Kim et al. 2011). The presence of EGCG in tea was also reported by Kim et al. (2011), and Yi et al. (2015). Peak 5 is another large peak and was identified as caffeine. The presence of caffeine in tea had been reported previously by Del Rio et al. (2004), and Kim et al. (2011). The last two peaks were identified as rutin and myricetin, respectively. The presence of rutin in tea was reported previously by Pękal et al. (2011), while Jeganathan et al. (2016) reported the presence of myricetin. Furthermore, several other unidentifiable peaks in the studied sample. The peaks could be other types of catechin such as epicatechin gallate (ECG) and epigallocatechin (EGC) as they are abundantly found in
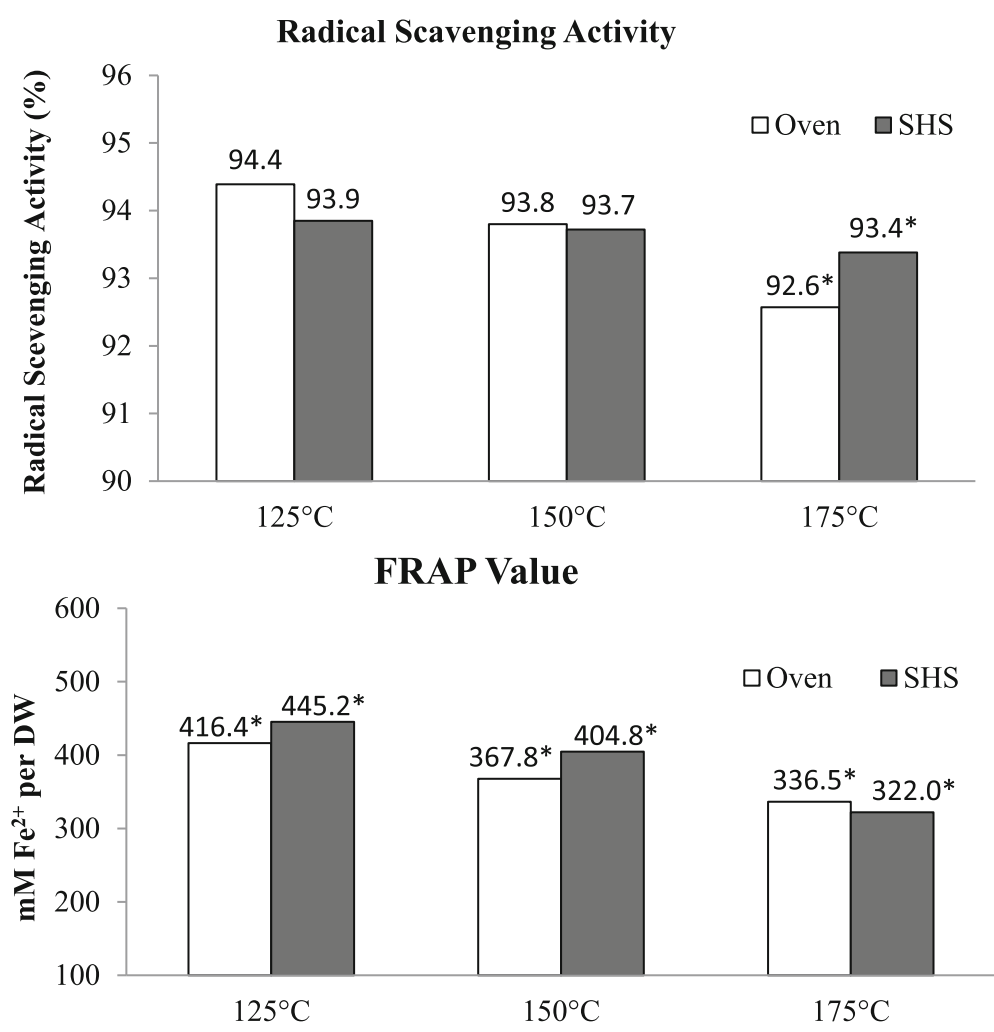

ORAC Value

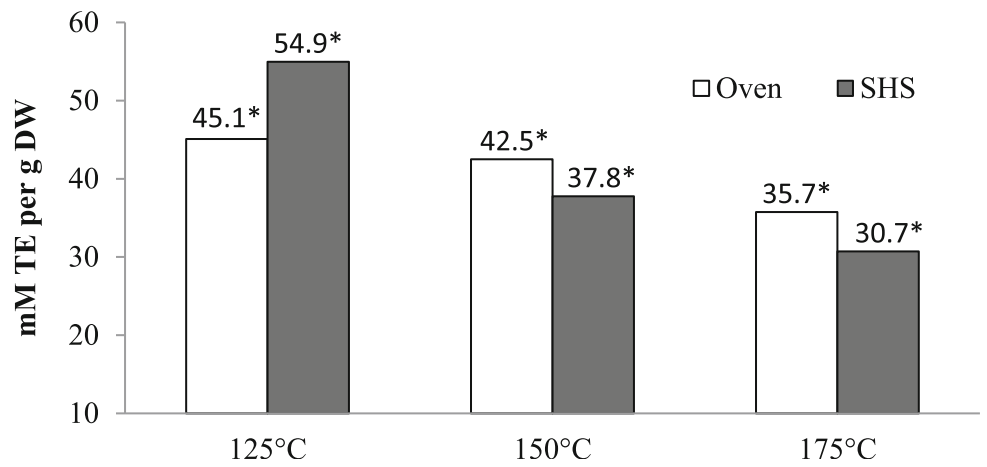

Fig. 2 Comparison of antioxidant capacity between oven dried and SHS dried tea leaves at different temperatures. $\left(^{*}\right)$ indicates significant differences $(p<0.05)$ between values at the same temperature based on independent sample t-test. (SHS = Superheated steam) 
tea leaves as reported by Lee et al. (2014) and Zhao et al. (2014). However, it could not be confirmed due to the lack of standard compounds for identification.

Overall, there was significant difference $(p<0.05)$ in the concentration of the phenolic compounds between the three drying methods. Freeze dried leaves showed the highest concentration for all listed compounds. Between oven dried sample and SHS dried leaves, the former method showed significantly higher $(p<0.05)$ concentration for four of the listed compounds (theobromine, epicatechin, EGCG, rutin). Gallic acid and caffeine concentrations were significantly higher $(p<0.05)$ in SHS dried sample. Myricetin showed no significant difference $(p>0.05)$ in concentration between the two methods.

In terms of drying methods, freeze dried tea leaves showed the highest concentration of the selected phenolic compounds. The reason for this is that the low temperature ensures better preservation of bioactive compounds and consequently a higher antioxidant activity (Samoticha et al. 2016). This would explain why the freeze-dried samples had higher concentration of the selected phenolic compounds and also the highest antioxidant capacity, total phenolic and flavonoid content. In addition, the samples that underwent oven drying and superheated steam drying had lower concentrations of the selected phenolic compounds than freeze dried samples which could indicate loss of phenolic compounds. As stated by Chan et al. (2009), thermal drying process caused a greater loss in phenol compounds compared to non-thermal drying process. During the drying process, activation of oxidative enzymes, such as polyphenoloxidase and peroxidase, may have led to the loss of phenolic complexes (Gümüşay et al. 2015). In addition, thermal degradation is also a possible reason for the loss of phenolic compounds in the sample (Maillard and Berset 1995; Méndez-Lagunas et al. 2017).

\section{Effect of drying temperature and duration on antioxidant capacity}

The antioxidant capacity, TFC, and TPC values obtained from tea leaves dried using both methods are shown in Figs. 2 and 3. At $125^{\circ} \mathrm{C}$ drying temperature, SHS dried tea leaves showed significantly higher $(p<0.05)$ antioxidant

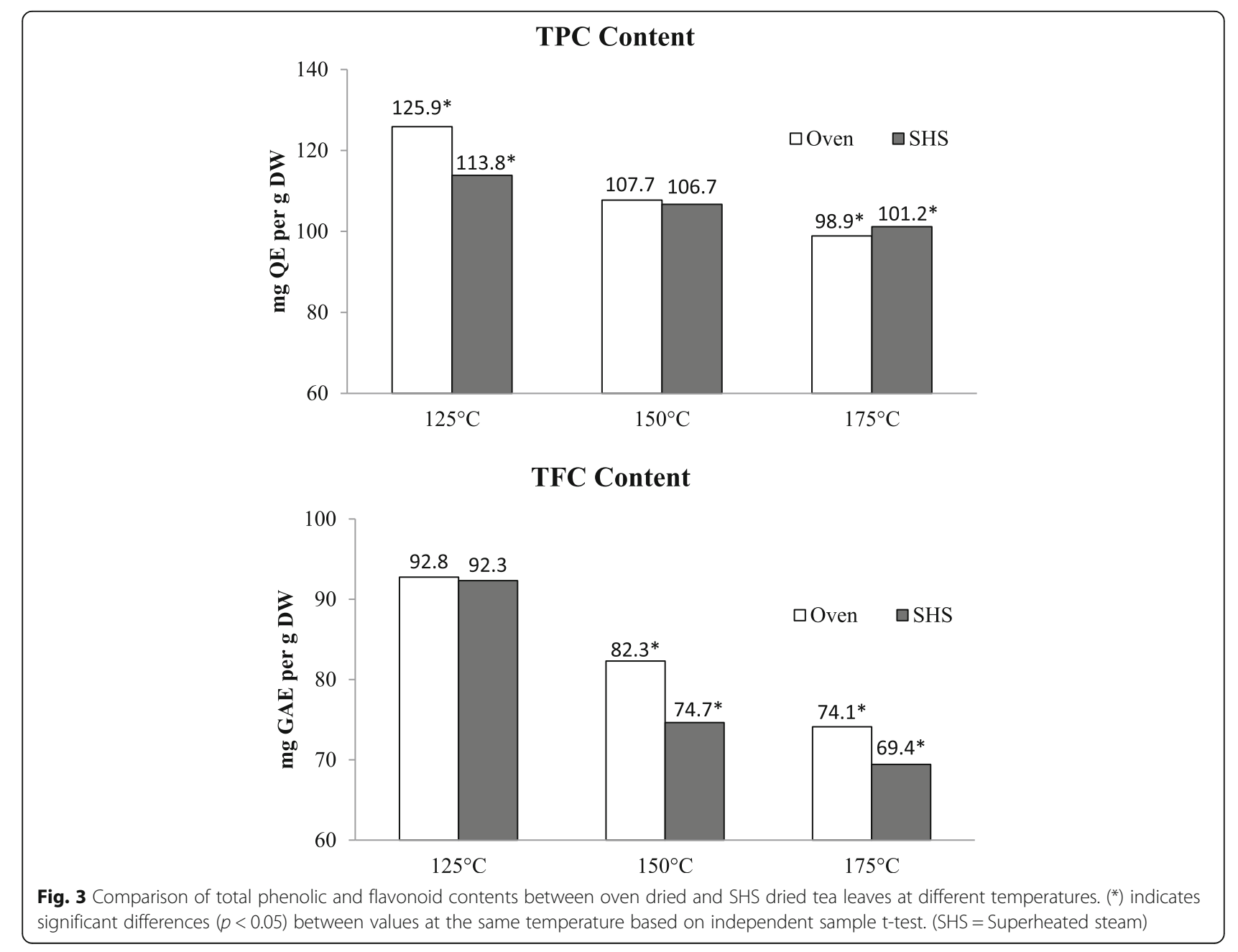


properties than oven dried leaves, according to the FRAP and ORAC values, while oven dried tea leaves showed significantly higher TPC. No significant differences $(p>0.05)$ were observed between leaves dried using both methods in terms of radical scavenging activity and TFC. Oven dried tea leaves showed significantly higher $(p<0.05)$ ORAC and TFC values than the leaves dried using SHS drying method, while leaves dried using SHS showed significantly higher FRAP value at $150^{\circ} \mathrm{C}$. No significant differences $(p>0.05)$ in radical scavenging activity and TPC were observed between leaves dried using both drying methods. Oven dried tea leaves also showed significantly higher $(p<0.05)$ FRAP, ORAC, and TFC values at $175^{\circ} \mathrm{C}$. Tea leaves dried using
SHS showed significantly higher $(p<0.05)$ radical scavenging activity and TPC.

Overall, tea leaves dried using SHS showed significantly higher FRAP and ORAC values than oven dried leaves at $125^{\circ} \mathrm{C}$. However, at $150^{\circ} \mathrm{C}$ and $175^{\circ} \mathrm{C}$, oven dried tea leaves had significantly higher antioxidant properties than SHS dried leaves. In addition, the antioxidant properties of the tea leaves dried using both methods decreased as the drying temperature increased. Similar results were reported by Katsube et al. (2009) and $\mathrm{Li}$ et al. (2017). Katsube et al. (2009) reported that the level of polyphenol compounds in air dried mulberry leaves significantly decreased at $70^{\circ} \mathrm{C}$ and above. In addition, $\mathrm{Li}$ et al. (2017) reported that the antioxidant
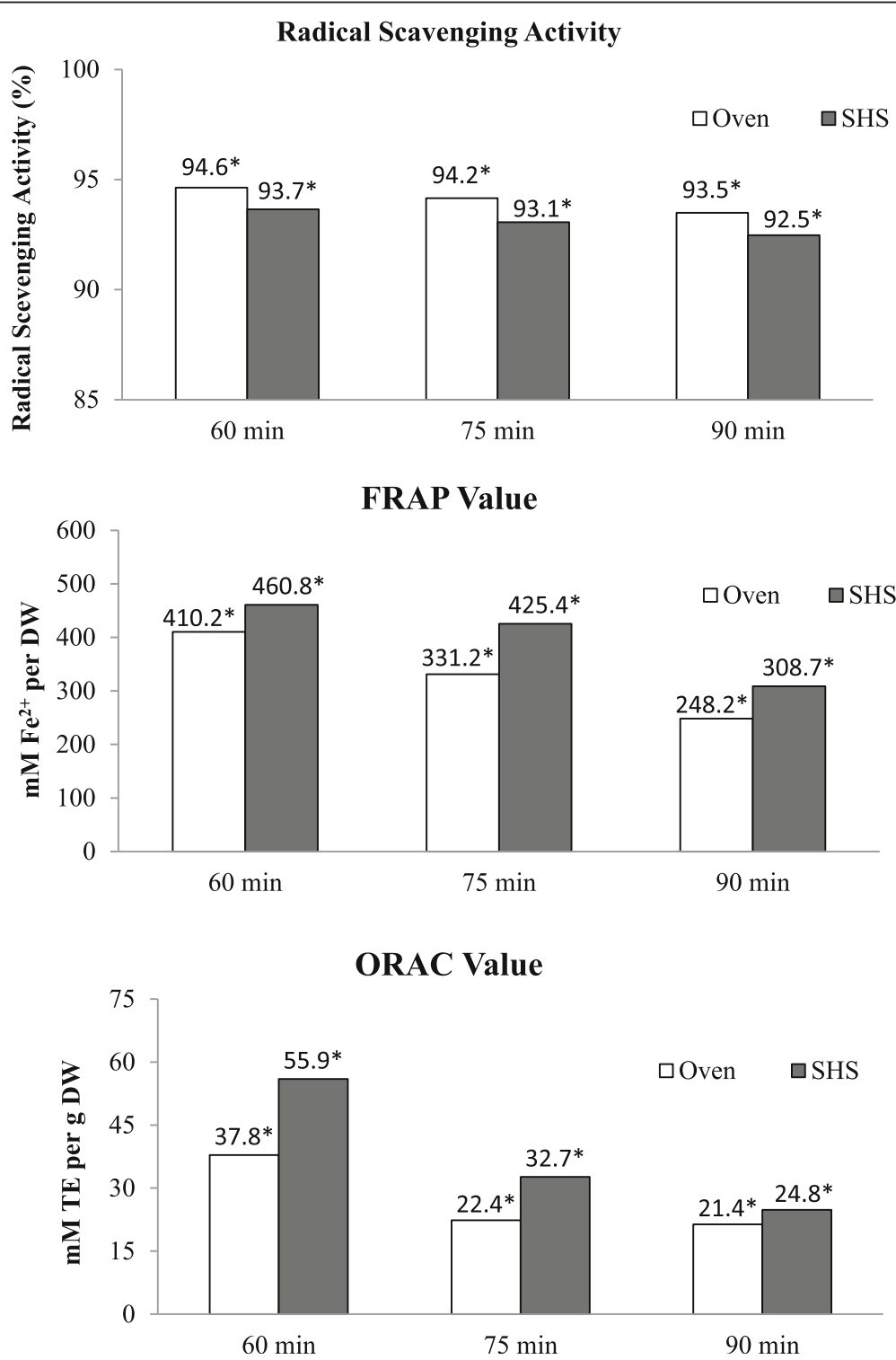

Fig. 4 Comparison of antioxidant capacity between oven dried and SHS dried tea leaves at different drying duration. $\left(^{*}\right)$ indicates significant differences $(p<0.05)$ between values at the same time based on independent sample t-test. (SHS = Superheated steam) 
capacity of licorice extract powder decreased as the drying temperature increased.

Drying processes, and in particular high temperature and long drying time, might destroy some of the phenol compounds ( $\mathrm{Li}$ et al. 2006) and promote a decrease in the antioxidant capacity (Garau et al. 2007; Chan et al. 2009). Our finding was in accordance with the statement in which there was a decrease in antioxidant properties as the drying temperature increased. In addition, according to Maillard and Berset (1995) and Méndez-Lagunas et al. (2017), the decrease in the phenolic content during drying at high temperature can be explained by three possible mechanisms which include the release of bound phenolic compounds, partial degradation of lignin leading to the release of phenolic acid derivatives, and the beginning of thermal degradation of the phenolic compounds. Hence, the decrease in antioxidant capacity in the dried samples could be due to the above mechanisms.

On the other hand, the present study contradicts with the results of previous studies. Udomkun et al. (2015) reported an increase in the total phenolic compound of papaya dried at increasing temperatures between $50{ }^{\circ} \mathrm{C}$ to $80^{\circ} \mathrm{C}$.Esparza-Martínez et al. (2016) also reported an increase in total phenol and flavonoid contents of lime waste as the drying temperature increases. Que et al. (2008) reported the formation of phenolic substances during drying at $70{ }^{\circ} \mathrm{C}$, and the formation might be due to the availability of precursors of phenolics by nonenzymatic inter-conversion between phenolic molecules; which increased the total phenol substances in the sample as the drying temperature increased. In addition, according to Samoticha et al. (2016), rapid and short heating may cause inactivation of oxidative enzymes and contribute to better preservation of phenolic compounds. However, the drying temperatures used in the present study might have been too high that it causes deterioration instead of formation of the phenolic compounds in the sample. This would explain the decrease in the antioxidant properties of the studied dried leaves.

The antioxidant capacity, TFC, and TPC values of tea leaves dried using both drying methods are shown in Figs. 4 and 5. No significant difference $(p>0.05)$ was

\section{TPC Content}

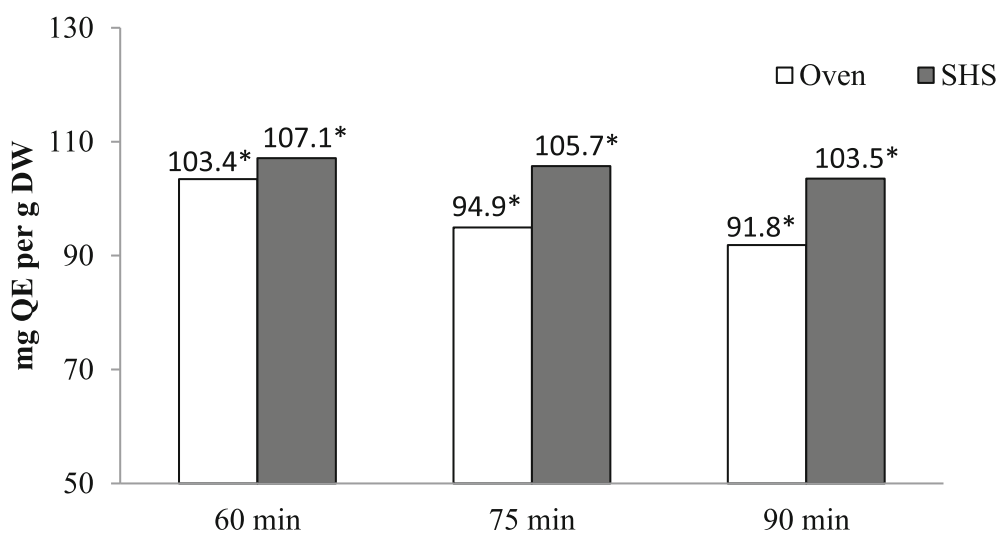

TFC Content

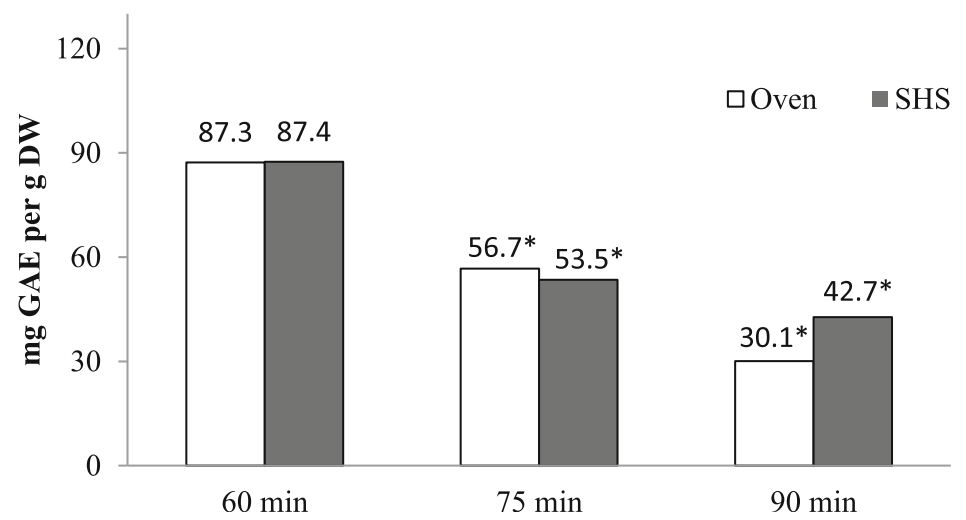

Fig. 5 Comparison of total phenolic and flavonoid contents between oven dried and SHS dried tea leaves at different drying duration. $\left(^{*}\right)$ indicates significant differences $(p<0.05)$ between values at the same time based on independent sample t-test. (SHS = Superheated steam) 
observed in the TFC value obtained by both methods at 60 min drying. Oven dried leaves showed significantly higher $(p<0.05)$ radical scavenging activity compared to SHS dried leaves at $60 \mathrm{~min}$ drying. At $75 \mathrm{~min}$ drying, oven dried leaves showed significantly higher $(p<0.05)$ radical scavenging activity and TFC value compared to SHS dried leaves. At 60 and $75 \mathrm{~min}$ drying, SHS dried leaves showed significantly higher $(p<0.05)$ FRAP, ORAC, and TPC values than oven dried leaves. A significantly higher $(p<0.05)$ value of FRAP, ORAC, TPC and TFC was obtained from the SHS dried leaves at $90 \mathrm{~min}$ drying. Oven dried leaves only showed significantly higher $(p<0.05)$ radical scavenging activity compared to SHS dried leaves.

Overall, tea leaves dried using SHS for 60, 75, and 90 min showed significantly higher $(p<0.05)$ FRAP, ORAC, and TPC values than that of oven dried tea leaves. Using SHS with its high drying rate, may have caused the inactivation of oxidative enzymes and contributed to better preservation of phenolic compounds due to rapid and short heating (Samoticha et al. 2016). A decrease in antioxidant properties of the sample was also observed in both drying methods as the drying duration increased. This was similar to the results of previous works involving different drying temperatures. According to Schieber et al. (2001) and Las Heras et al. (2014), the loss of flavonoids during drying might be due to the drying temperatures and time. Kuljarachanan et al. (2009) stated that phenolic compounds decreased steadily with drying times. Drying time would increase the exposure of the antioxidant compounds to heat, which leads to a greater loss in the antioxidant compounds due to structural change (Li et al. 2017) or thermal degradation (MéndezLagunas et al. 2017). Samoticha et al. (2016) reported that fruits dried using thermal drying at $70^{\circ} \mathrm{C}$ had a higher content of polyphenols and anthocyanins, and antioxidant activity than that of fruits dried at $50^{\circ} \mathrm{C}$.

\section{Conclusion}

Tea leaves dried using SHS exhibited significantly higher ORAC, FRAP, and TFC values than that of conventional oven. Oven dried leaves showed significantly higher percentage of radical scavenging activity than that of SHS dried fruits. Oven method retained higher antioxidant properties compared to SHS at both different drying temperatures and times. Further research on the effect of drying conditions used during drying process on individual compounds should be conducted in the future for better understanding.

\section{Abbreviations}

AAPH: Azo-bis(2-amidinopropane) dihydrochloride; AUC: Area under the curve; DPPH: 2,2-Diphenylpicrylhydrazil; DW: Dry weight; FRAP: Ferric reducing activity of plasma; GAE: Gallic acid equivalent; ORAC: Oxygen radical absorbance capacity; PGR: Pyrogallol red; QE: Quercetin equivalent;
SHS: Superheated steam; TE: TROLOX equivalent; TFC: Total flavonoid content; TPC: Total phenolic content; TPTZ: 2,4,6-Tris(2-pyridyl)-s-triazine; TROLOX: 6-hydroxy-2,5,7,8-tetramethylchroman-2-carboxylic acid

\section{Acknowledgements}

The authors would like to acknowledge the Graduate School of Life Science and System Engineering of Kyushu Institute of Technology and School of Graduate Studies of UPM for providing financial support during research attachment at KIT in 2015

\section{Authors' contributions}

Roslan, A.S. designed the experiments, collected and analyzed the data, and prepared the draft of the manuscript. Ismail, A. and Azlan, A. have supervised this study, read and edited the manuscript, and provided equipment for the experiments. Ando, Y. also provided the equipment and the laboratory where the experiments were conducted. The author(s) read and approved the final manuscript.

\section{Funding}

This study was supported by the School of Graduate Studies and the Department of Nutrition and Dietetics of Universiti Putra Malaysia (Malaysia), in collaboration with the Graduate School of Life Science and System Engineering of Kyushu Institute of Technology (Japan).

Availability of data and materials

Data are available upon request by contacting the authors.

\section{Competing interests}

The authors declare that they have no competing interests.

\section{Author details}

${ }^{1}$ Department of Nutrition and Dietetics, Faculty of Medicine and Health Sciences, Universiti Putra Malaysia, 43400 Serdang, Selangor, Malaysia. ${ }^{2}$ Department of Biological Functions Engineering, Graduate School of Life Science and Systems Engineering, Kyushu Institute of Technology, 2-4 Hibikino, Wakamatsu-ku, Kitakyushu, Fukuoka 808-0196, Japan.

Received: 14 January 2020 Accepted: 11 March 2020

Published online: 07 April 2020

\section{References}

Abeywickrama, R. (2015). In vitro assessment of antioxidant capacity of Sri Lankan black tea (Camellia sinensis L.) during storage and its relation to phenolic content. International Journal of Pharmaceutical Chemistry and Toxicology, 1, $42-46$

Atoui, A. K., Mansouri, A., Boskou, G., \& Kefalas, P. (2005). Tea and herbal infusions: Their antioxidant activity and phenolic profile. Food Chemistry, 89, 27-36.

Baba, S. A., \& Malik, S. A. (2015). Determination of total phenolic and flavonoid content, antimicrobial and antioxidant activity of a root extract of Arisaema jacquemontii Blume. Journal of Taibah University for Science, 9, 449-454.

Benzie, I.F.F., \& Strain, J.J. (1996). The ferric reducing ability of plasma (FRAP) as a measure of "antioxidant power': The FRAP Assay. Analytical Biochemistry, 239, 70-76.

Brand-Williams, W., Cuvier, M. E., \& Berset, C. (1995). Use of a free radical method to evaluate antioxidant activity. LWT -Food Science and Technology, 28, 25-30.

Cádiz-Gurrea, M. L., Fernández-Arroyo, S., \& Segura-Carretero, A. (2014). Pine bark and green tea concentrated extracts : Antioxidant activity and comprehensive characterization of bioactive compounds by HPLC-ESI-QTOFMS. International Journal of Molecular Sciences, 15, 20382-20402.

Chan, E. W. C., Lim, Y. Y., Chong, K. L., Tan, J. B. L., \& Wong, S. K. (2010). Antioxidant properties of tropical and temperate herbal teas. Journal of Food Composition and Analysis, 23, 185-189.

Chan, E. W. C., Lim, Y. Y., Wong, S. K., Lim, K. K., Tan, S. P., Lianto, F. S., \& Yong, M. $Y$. (2009). Effects of different drying methods on the antioxidant properties of leaves and tea of ginger species. Food Chemistry, 113, 166-172.

Chew, L.Y., Prasad, K.N., Amin, I., Azrina, A., \& Lau, C.Y. (2011). Nutritional composition and antioxidant properties of Canarium odontophyllum Miq. (dabai) fruits. Journal of Food Composiiton and Analysis, 24, 670-677.

Chopade, V. V., Phatak, A. A., Upaganlawar, A. B., \& Tankar, A. A. (2008). Green tea (Camellia sinensis): Chemistry, traditional, medicinal uses and its pharmacological activities- a review. Pharmacognosy Reviews, 3, 157-162. 
Del Rio, D., Stewart, A. J., Mullen, W., Burns, J., Lean, M. E., Brighenti, F., \& Crozier, A. (2004). HPLC - MS analysis of phenolic compounds and purine alkaloids in green and black tea. Journal of Agriculture and Food Chemistry, 10, 28072815.

Do, Q. D., Angkawijaya, A. E., Tran-Nguyen, P. L., Huynh, L. H., Soetaredjo, F. E., Ismadji, S., \& Ju, Y. H. (2014). Effect of extraction solvent on total pheno content, total flavonoid content, and antioxidant activity of Limnophila aromatica. Journal of Food and Drug Analysis, 22, 296-302.

Esparza-Martínez, F. J., Miranda-López, R., \& Guzman-Maldonado, S. H. (2016). Effect of air-drying temperature on extractable and non-extractable phenolics and antioxidant capacity of lime wastes. Industrial Crops and Products, 84, 1-6.

Garau, M. C., Simal, S., Rosselló, C., \& Femenia, A. (2007). Effect of air-drying temperature on physico-chemical properties of dietary fibre and antioxidant capacity of orange (Citrus aurantium v. Canoneta) by-products. Food Chemistry, 104, 1014-1024.

Gümüşay, Ö. A., Borazan, A. A., Ercal, N., \& Demirkol, O. (2015). Drying effects on the antioxidant properties of tomatoes and ginger. Food Chemistry, 173, 156162.

Gupta, S., Saha, B., \& Giri, A. K. (2002). Comparative antimutagenic and anticlastogenic effects of green tea and black tea : A review. Mutation Research, 512, 37-65.

Hajimahmoodi, M., Hanifeh, M., Oveisi, M. R., Sadeghi, N., \& Jannat, B. (2008). Determination of total antioxidant capacity of green teas by the ferric reducing/antioxidant power assay. Iranian Journal of Environmental Health Science and Engineering, 5, 167-172.

Hwang, E. S., \& Thi, N. D. (2014). Antioxidant contents and antioxidant activities of hot water extracts of Aronia (Aronia melancocarpa) with different drying methods. Korean Journal of Food Science and Technology, 46, 303-308.

Jeganathan, B., Punyasiri, P. A. N., Kottawa-Arachchi, J. D., Ranatunga, M. A. B., Abeysinghe, I. S. B., Gunasekare, M. T. K., \& Bandara, B. M. R. (2016). Genetic variation of flavonols Quercetin, Myricetin, and Kaempferol in the Sri Lankan tea (Camellia sinensis L.) and their health-promoting aspects. International Journal of Food Science, 2016, 1-9.

Katsube, T., Tsurunga, Y., Sugiyama, M., Furuno, T., \& Yamazaki, Y. (2009). Effects of air drying temperature on antioxidant capacity and stability of polyphenolic compounds in mulberry (Morus alba L.) leaves. Food Chemistry, 113, 964-969.

Kaur, K., \& Singh, A. K. (2014). Drying kinetics and quality characteristics of beetroot slices under hot air followed by microwave finish drying. African Journal of Agricultural Research, 12, 1036-1044.

Kim, Y., Goodner, K. L., Park, J. D., Choi, J., \& Talcott, S. T. (2011). Changes in antioxidant phytochemicals and volatile composition of Camellia sinensis by oxidation during tea fermentation. Food Chemistry, 129, 1331-1342.

Kuljarachanan, T., Devahastin, S., \& Chiewchan, N. (2009). Evolution of antioxidant compounds in lime residues during drying. Food Chemistry, 113, 944-949.

Las Heras, R. M., Heredia, A., Castelló, M. L., \& Andrés, A. (2014). Influence of drying method and extraction variables on the antioxidant properties of persimmon leaves. Food Bioscience, 6, 1-8.

Lee, L. S., Kim, S. H., Kim, Y. B., \& Kim, Y. C. (2014). Quantitative analysis of major constituents in green tea with different plucking periods and their antioxidant activity. Molecules, 19, 9173-9186.

Li, B. B., Smith, B., \& Hossain, M. M. (2006). Extraction of phenolics from citrus peels II. Enzyme-assisted extraction method. Separation and Purification Technology, 48, 189-196.

Li, W., Xiang, F., Zhong, M., Zhou, L., Liu, H., Li, S., \& Wang, X. (2017) Transcriptome and metabolite analysis identifies nitrogen utilization genes in tea plant (Camellia sinensis). Scientific Reports, 7, 1693.

Li, X., \& Zhu, X. (2016). Tea : Types, production, and trade. The Encyclopedia of Food and Health, 5, 279-282.

López-Alarcón, C., Ortíz, R., Benavides, J., Mura, E., \& Lissi, E. (2011). Use of the ORAC-Pyrogallol red/ORAC-fluorescein ratio to assess the quality of antioxidants in Chilean wines. Journal of the Chilean Chemical Society, 56, 764-767.

Mahmood, T., Akhtar, N., \& Khan, B. A. (2010). The morphology, characteristics, and medicinal properties of Camellia sinensis tea. Journal of Medicinal Plants Research, 19, 2028-2033.

Maillard, M. N., \& Berset, C. (1995). Evolution of antioxidant activity during kilning: Role of insoluble bound phenolic acids of barley and malt. Journal of Agriculture and Food Chemistry, 43, 1789-1793.

Méndez-Lagunas, L., Rodríguez-Ramírez, J., Cruz-Gracida, M., Sandoval-Torres, S., \& Barriada-Bernal, G. (2017). Convective drying kinetics of strawberry (Fragaria ananassa): Effects on antioxidant activity, anthocyanins and total phenolic content. Food Chemistry, 230, 174-181.

Nistor, O. V., Seremet, L., Andronoiu, D. G., Rudi, L., \& Botez, E. (2017). Influence of different drying methods on the physicochemical properties of red beetroot (Beta vulgaris L. Var. Cylindra). Food Chemistry, 236, 59-67.

Nor Qhairul Izreen, M. N., \& Mohd Fadzelly, A. B. (2013). Phytochemicals and antioxidant properties of different parts of Camellia sinensis leaves from Sabah tea plantation in Sabah, Malaysia. International Food Research Journal, 20, 307-312.

Nurul Nadiah, M., Amin, I., Azrina, A., Muhajir, H., \& Fouad, A.H. (2014). Effect of dabai (Canarium odontophyllum) fruit extract on biochemical parameters of induced obese-diabetic rats. Journal of Functional Foods, 8, 139-149.

Pękal, A., Dróżdż, P., Biesaga, M., \& Pyrzynska, K. (2011). Evaluation of the antioxidant properties of fruit and flavoured black teas. European Journal of Nutrition, 50, 681-688.

Prabhakaran Nair, K. P. (2010). Tea (Camellia sinensis L.). In The Agronomy and Economy of Important Tree Crops of the Developing World (pp. 275-300). Burlington: Elsevier Inc.

Prasad, K. N., Chew, L. Y., Khoo, H. E., Yang, B., Azrina, A., \& Amin, I. (2010). Carotenoids and antioxidant capacities from Canarium odontophyllum Miq. fruit. Food Chemistry, 124, 1549-1555.

Que, F., Mao, L., Fang, X., \& Wu, T. (2008). Comparison of hot air-drying and freeze-drying on the physicochemical properties and antioxidant activities of pumpkin (Cucurbita moschata Duch.) flours. International Journal of Food Science and Technology, 43, 1195-1201.

Rafidah, H., Ando, Y., Amin I., Shirai, Y., \& Mohd Ali, H. (2014). Enhanced polyphenol content and antioxidant capacity in the edible portion of avocado dried with superheated-steam. International Journal of Advanced Research, 8, 241-248.

Rumruaytum, P., Borompichaichartkul, C., \& Kongpensook, V. (2014). Effect of drying involving fluidisation in superheated steam on physicochemical and antioxidant properties of Thai native rice cultivars. Journal of Food Engineering, 123, 143-147.

Samoticha, J., Wojdyło, A., \& Lech, K. (2016). The influence of different drying methods on the chemical composition and antioxidant activity in chokeberries. LWT - Food Science and Technology, 66, 484-489.

Schieber, A., Stintzing, F. C., \& Carle, R. (2001). By-products of plant food processing as a source of functional compounds recent developments. Trends in Food Science and Technology, 12, 401-413.

Seeram, N. P., Henning, S. M., Niu, Y., Lee, R., Scheuller, H. S., \& Heber, D. (2006). Catechin and caffeine content of green tea dietary supplements and correlation with antioxidant capacity. Journal of Agriculture and Food Chemistry, 54, 1599-1603.

Somjai, T., Achariyaviriya, S., Achariyaviriya, A., \& Namsanguan, K. (2009). Strategy for longan drying in two-stage superheated steam and hot air. Journal of Food Engineering, 95, 313-321.

Sultana, B., Anwar, F., \& Ashraf, M. (2009). Effect of extraction solvent / technique on the antioxidant activity of selected medicinal plant extacts. Molecules, 14 , 2167-2180.

Udomkun, P., Nagle, M., Mahayothee, B., Nohr, D., Koza, A., \& Müller, J. (2015). Influence of air drying properties on non-enzymatic browning, major bioactive compounds and antioxidant capacity of osmotically pretreated papaya. LWT - Food Science and Technology, 60, 914-922.

Yi, T., Zhu, L., Peng, W. L., He, X. C., \& Chen, H. L. (2015). Comparison of ten major constituents in seven types of processed tea using HPLC-DAD-MS followed by principal component and hierarchical cluster analysis. Food Science and Technology, 62, 194-201.

Yuan, J. M., Sun, C., \& Butler, L. M. (2011). Tea and cancer prevention: Epidemiological studies. Pharmacological Research, 64, 123-135.

Zhao, C., Li, C., Liu, S., \& Yang, L. (2014). The galloyl catechins contributing to main antioxidant capacity of tea made from Camellia sinensis in China. The Scientific World Journal, 2014, 863984

Zzaman, W., Bhat, R., \& Tajul, A. Y. (2013). Effect of superheated steam roasting on the phenolic antioxidant properties of cocoa beans. Journal of Food Processing and Preservation, 2013, 1-7.

\section{Publisher's Note}

Springer Nature remains neutral with regard to jurisdictional claims in published maps and institutional affiliations. 